\title{
Production Synergies, Technology Adoption, Unemployment, and Wages*
}

\author{
Gwen Eudey \\ Board of Governors \\ Washington, DC 20551 \\ gwen.eudey@frb.gov
}

\author{
Miguel Molico \\ University of Western Ontario \\ London, Ontario, Canada N6A5C2 \\ mmolico@julian.uwo.ca
}

April 2001

\begin{abstract}
Recent empirical work reveals considerable heterogeneity in the use of technologies within industries, suggesting technology adoption depends on factors other than industry type. We present a model in which the factors that lead to heterogenous technology adoption play a key economic role in explaining other aspects of the U.S. economy that have been the focus of recent theoretical work, including wage and technology dispersion within and between skill groups and the U-shaped pattern of measured productivity that many other researchers have attributed to learning economies or to production externalities.
\end{abstract}

*The views expressed here are those of the authors and do not necessarily reflect those of the Federal Reserve Board or the Federal Reserve System. We thank participants at the Essex Search Conference and the meetings of the Society of Economic Dynamics for their comments. 


\section{Introduction}

Recent empirical work with firm-level data reveals considerable heterogeneity in the use of technologies within industries. This evidence suggests that there may be no single best capital vintage for any firm, but rather that the optimal technology decision may depend on factors other than industry type. We present a model in which the factors that lead to heterogeneous technology adoption play a key economic role in explaining other aspects of the U.S. economy that have been the focus of recent theoretical work, including wage dispersion within and between skill groups and the U-shaped pattern of measured productivity that many other researchers have attributed to learning economies or to production externalities. $^{1}$

There are three key assumptions in the model: (1) Production depends on the synergy between the characteristics of the firm, the technology, and the worker; (2) Labor market frictions affect the expected return from search, and therefore the makeup of acceptable matches; and (3) Workers are heterogenous. Technology adoption is endogenous on the production synergies of potential matches, the expected return from search of any potential match, and the cost of switching technologies. Technology adoption immediately affects current production, and there is a one-time immediate fixed cost to switching technologies; this cost is shared by the worker and firm in the division of the joint surplus. The timing is as follows. Firms, holding a technology type, randomly meet workers on the labor market. The pair jointly determine what technology adoption decision, including the possibility of maintaining the current holding, would maximize their joint surplus in the event of a match. If the joint surplus would be positive, the match is formed.

The model has no analytical solution. We numerically solve the model under alternative specifications for the cost of capital, skill-composition of the workforce, and the number of available technologies. These exercises are meant to demonstrate the plausible effect of the significant drop in the cost of hightech capital, the increase in college education, and the technological revolution of the 1970s-1990s might have effected technology adoption, wage dispersion, unemployment, and productivity in both the intermediate and long-run. In summary, we find that because technology adoption depends on the cost and availability of complementary inputs, any change in fundamentals can affect the matching decision by firms and workers. Any disruption to the matching decision will, in turn, lead to a fall in productivity until the economy returns to a balance in which the number of match breaks equals the number formed. Importantly, we find the U-shaped pattern of productivity can be the result of any economic shock that affects the allocation of workers across firms: a Ushaped pattern of productivity may not be the result of "creative destruction" nor of any technological innovation. Moreover actual creative destruction in our model-a temporary fall in productivity as the economy responds to a productiv-

\footnotetext{
${ }^{1}$ See Greenwood and Jovanovic (1998) for an application of the learning model to the IT revolution; see Aghion and Howitt (1994) for a model in which creative destruction is generated by a negative production externality following technology adoption.
} 
ity shock-is not the result of learning economies nor of any (explicit) production externalities, but rather purely the consequence of labor market frictions.

The introduction continues with a review of the empirical evidence and related litereature. The model is presented in Section 2. In Section 3 we define an equilibrium and discuss its computation. Numerical solutions are discussed in Section 4, followed by a discussion of dynamics between equilibria in Section 5. Section 6 discusses the relevance of the model to study of U.S. data over the transition to what has been dubbed the "new economy."

\subsection{Worker and firm heterogeneity}

\subsubsection{Heterogenous production practices within industries}

The term "production practice" refers to technologies which affect the productivity of the worker-firm match, but which are not inherent to (nonseparable from) either. It is clear that the usefulness of technologies varies across industries. Empirical work which focuses on technology adoption tries to control for industry effects, with focus on other influences on the technology adoption decision-including cost, market niche of the firm, and workforce characteristics.

Doms, Dunne, and Troske (1997), in a study which links the Survey of Manufacturing Technology to the Worker-Establishment Characteristic Database, find a correlation between the level of technology use and worker skill within industries; moreover, by looking at changes in technology adoption and in the skill level of the firm's workforce, they find that it is firms that have already employed skilled workers that buy high-tech capital, and not the other way around. In other words, the technology adoption decision depends on the current worker-firm match. ${ }^{2}$ Other surveys which document heterogeneity in technology adoption within manufacturing industries include Siegel (1999) and Hwang and Weil (1999).

Our interest in heterogenous production practices suggests a departure from the "vintage capital" framework in which there is a single best technology for any type of firm. Acemoglu and Shimer (1999) present a model of wage and technology dispersion in which, under the assumption that workers heterogenously engage in search intensity, firms will heterogenously engage in capital development in order to attract (heterogenously) informed workers. Acemoglu (1998) and Kiley (1999) both have interesting search models in which technology adoption is endogenous on the relative supply of skilled workers. In both models the return to developing capital goods that are complementary to skilled labor rises with an increase in the relative supply of educated workers. In Acemoglu's model there are two final goods, each type produced in only one way with one type of worker; as in Aghion and Howitt (1994), the ability of the firm

\footnotetext{
${ }^{2}$ Notably, however, there is one exception to this general result: purchase of computer technologies leads to skill-upgrading (through retraining or otherwise-their data do not indicate) of the workforce. Siegel (1999) also finds that adoption of "linked advanced manufacturing technologies" (largely database management systems) leads training of existing personell. One logical extension of our model would be to incorporate learning effects or to otherwise endogenize worker skills.
} 
to update to the best capital vintage arrives idiosyncratically, so that heterogeneous production practices are the result of an exogenous timing constraint, rather than by choice. In the Kiley model there is one final good that can be produced in two ways-using skilled or unskilled workers with complementary capital inputs. Specialization in the pairing of skilled and unskilled workers with only one type of technology makes it so that neither the Acemoglu nor the Kiley model offers a unified explanation of wage dispersion within skill groups as well within firm type.

\subsubsection{Wage dispersion across and between worker types}

Chinhui, Murphy, and Pierce (1993) document that returns to education (dispersion between worker types) fell in the 1970s and then rose in the 1980s, whereas wage dispersion within education classes rose over both samples. Although the authors find that most of the wage distribution is explained by education, there are essentially two theories which describe wage dispersion within education classes: the first is that there are unobservable skills that are not related to education, the second is that labor market frictions allow workers with identical characteristics to nonetheless earn different returns to their labor input.

In our framework workers can be divided into groups with different skills; these skills might include attributes which are unobservable to the econometrician in the applied labor research, but all skills are assumed to observable to firms in our model economy. Relative demand for, and productivity of, workers with different skills can lead to wage dispersion between skill groups. Search frictions in the labor market can lead to wage dispersion within skill groups. This aspect of the model is also found in Albrecht and Vroman (1999).

\section{The Model}

\subsection{The Environment}

Time is discrete. The economy is populated by a continuem of infinitely lived workers with mass normalized to unity. Workers are of $L$ distinct types, indexed $l=1, \ldots, L$. Let $\gamma_{l}$ denote the fraction of workers of type $l$. At any point in time, workers can either be employed or unemployed. While unemployed, agents enjoy flow utility $b \cdot p(t)>0$ where $p(t)$ grows at constant rate $g$, the rate of technological progress. While employed, agents get paid wages. Similarly, there is a continuum of firms with mass $F$. Firms are of $I$ distinct types, indexed $i=1, \ldots, I$. All firms produce an identical good (utility). Neither workers or firms can change their type ${ }^{3}$. Agents are impatient and discount the future at discount factor $0<\beta<1$.

To produce output a firm must be matched with a worker and use some technology. There is a menu of available technologies, indexed $z=1, \ldots, Z$.

\footnotetext{
${ }^{3}$ For the sake of simplicity, the type of an agent is viewed here as an intrinsic and unchangeable characteristic. Allowing agents to choose or change their type, say through training, would be an interesting extension.
} 
Technology vintage is denoted by a subscript; a new vintage arrives each period and offers an increase in any match synergy at rate $g$. The quantity of output which can be produced in any given match depends on the characteristics of the firm, the worker, and the technology adopted. Potential output is given by a matrix of production synergies, $y_{t}\left(i, z_{T}, l\right)$ where $T \leq t$.

The synergy model is designed to reflect the fact that firms may have many alternative production methods at their disposal, and that the optimal production method will depend on the availability of complementary labor inputs (distribution of unemployed workers across type).

We assume that technologies are rankable for all firm and worker pairs. ${ }^{4,5}$ Furthermore, technologies are costly. Holding a technology while matched involves a per period operating cost of $h c \cdot p(t)>0$. In addition, there is a fixed cost to adopting (switching to) a new technology. ${ }^{6}$ Let $s c\left(z^{\prime}, z\right) \cdot p(t)$ denote the cost of switching from technology $z$ to $z^{\prime}$, regardless of the vintage of either technology. We assume that $\operatorname{sc}\left(z_{t}, z_{T}\right)>0, \operatorname{sc}\left(z_{t}^{\prime}, z_{T}\right)>0$, and $\operatorname{sc}\left(z_{t}^{\prime}, z_{t}\right)>0$ for $z^{\prime} \neq z, t \neq T \cdot{ }^{7}$ Also, let $s c(z, \emptyset) \cdot p(t)>0$ denote the cost of adopting technology $z$ (of any vintage) when the firm is not holding any technology (new entrant). ${ }^{8}$ Technologies become available for production as soon as they are acquired.

We assume a search friction in the labor market. Workers and firms meet randomly. The arrival of a suitable match depends on the rate at which workers and firms meet as well as the probability that the potential match is desirable. The probability that an worker (firm) meets a firm (worker) of a certain type is equal to the probability that it meets someone times the probability that that vacant firm (unemployed worker) is of that particular type. Following Mortensen and Pissarides (1998) we characterize the arrival of meetings as a matching function

$$
m\left(\frac{v}{u}\right)=F^{\alpha}\left(\frac{v}{u}\right)^{a}
$$

\footnotetext{
${ }^{4}$ In principle, in case of indifference between technologies, one could assume the use of a randomization mechanism (lottery) to solve the technology adoption decision problem, but there is little insight gained from the added complication.

${ }^{5}$ The production matrix could be defined to reflect the notion that there is a single best technology which would, all other things being equal, maximize output for all worker-firm pairs (a vintage capital representation), or that there is a different best technology for each firm type, regardless of the worker with which the firm type is paired (vintage capital by industry or other firm characteristic). Defining the production matrix in either of those ways eliminates the technology adoption decision problem for the worker-firm pair; for this reason the framework nests those models in which technology is an imbedded firm characteristic.

${ }^{6}$ The specification is quite general - the cost of switching from a to $b$ may differ from that of switching from $\mathrm{b}$ to $\mathrm{a}$, and may differ from the cost of purchasing an entry technology.

${ }^{7} \mathrm{~A}$ model in which firms costlesslly switch to a high-productivity technology upon meeting a skilled worker is presented in Shi (1998).

${ }^{8}$ We assume that new firms can enter the labor market by purchasing some technology. Unrestricted entry implies, that in equilibrium, the value of a vacancy is driven down to the cost of purchasing that technology. This in turn implies that no vacant firm has an incentive to switch technologies.
} 
where $v$ and $u$ are the vacancy and unemployment rates, respectively. ${ }^{9}$ For simplicity define $\theta \equiv \frac{v}{u}$, a measure of market tightness. As $\theta$ rises, workers are more likely to meet with firms, and $m(\theta)$ is the function that characterizes that arrival rate. For firms, the arrival rate of unemployed workers is equal to $\frac{m(\theta)}{\theta}$; the arrival rate falls with a rise in $\theta$.

Let $f_{i z_{T}, t}$ denote the fraction of vacant firms that are of type $\left(i, z_{T}\right)$ at the begining of period $t$. Similarly, let $f_{l, t}$ denote the fraction of unemployed workers that are of type $l$ at the begining of period $t$. At time $t$, a worker faces an arrival rate of vacant firms of type $\left(i, z_{T}\right)$ given by $m\left(\theta_{t}\right) \cdot f_{i z_{T}, t}$. Similarly a firm faces an arrival rate of unemployed workers of type $l$ equal to $\frac{m\left(\theta_{t}\right)}{\theta_{t}} \cdot f_{l, t}$.

At the beginning of each period existing matches are exogenously randomly terminated with probability $\delta$.

\subsection{Matching, technology adoption and surplus sharing}

We define the net surplus of a match to be the gain of forming the match over and above the expected value of continued search. Let $L_{t}\left(i, z_{T}, l\right)$ denote the expected discounted lifetime utility of a worker of type $l$ that enters period $t$ employed by a firm of type $i$ holding technology $z_{T}$, and $U_{t}(l)$ denote the expected lifetime utility of an unemployed worker of type $l$ at the end of period $t$. Similarly, let $O_{t}\left(i, z_{T}, l\right)$ denote the value of a firm of type $i$ that enters period $t$ matched with a worker of type $l$ and holding technology $z$, and $V_{t}\left(i, z_{T}\right)$ denote the value of a vacant firm of type $\left(i, z_{T}\right)$ at the begining of period $t$. The net surplus of a match, at time $t$, between a worker of type $l$ and a firm of type $i$ currently holding technology $z_{T}$, conditional on switching to technology $z_{\tau}^{\prime}$ is defined to be:

$$
\begin{aligned}
S_{t}\left(i, z^{T}, l \mid z_{\tau}^{\prime}\right) \equiv & y_{t}\left(i, z_{\tau}^{\prime}, l\right)-h c \cdot p(t)-s c\left(z_{\tau}^{\prime}, z_{T}\right) \cdot p(t)+\beta L_{t+1}\left(i, z_{\tau}^{\prime}, l\right)-U_{t}(l) \\
& +\beta O_{t+1}\left(i, z_{\tau}^{\prime}, l\right)-\beta V_{t+1}\left(i, z_{s}^{\prime \prime}\right) .
\end{aligned}
$$

where $z_{s}^{\prime \prime}$ is the technology that the firm will continue to search with should the match not be formed.

When an unemployed worker and a vacant firm meet they must decide whether or not to match conditional on their optimal technology adoption decision. Agents must first determine which technology would maximize the net surplus of the match. Let $\zeta_{t}\left(i, z_{T}, l\right)$ denote such technology, i.e.,

$$
\zeta_{t}\left(i, z_{T}, l\right) \equiv \arg \max _{z_{\tau}^{\prime}} S_{t}\left(i, z_{T}, l \mid z_{\tau}^{\prime}\right)
$$

\footnotetext{
${ }^{9}$ Alternatively, the matching function can be expressed in terms of vacancy and unemployement levels.
}

$$
M(V C, U N)=V C^{\alpha} U N^{\alpha}
$$


Given the assumption that technologies are rankable for all firm and worker pair, $\zeta$ is a singleton. If, conditional on the optimal technology adoption decision, the net surplus of the match is nonnegative, $S_{t}\left[i, z_{T}, l \mid \zeta_{t}\left(i, z_{T}, l\right)\right] \geq 0$, then the match is formed and the optimal technology, $\zeta_{t}\left(i, z_{T}, l\right)$, is adopted. Production occurs immediately using the optimal technology and the surplus is shared between the worker and the firm according to Nash bargaining. The Nash assumption is convenient because if the match is acceptable for one party, it is acceptable to both, and it reduces bilateral bargaining to a rule. Let $S W_{t}\left[i, z_{T}, l \mid \zeta\left(i, z_{T}, l\right)\right]$ denote the net surplus of a worker of type $l$ from an acceptable match with a firm of type $i$ currently holding technology $z_{T}$ conditional on adopting the optimal technology, and $\pi$ denote the worker's share of the total net surplus. Then,

$$
\begin{aligned}
S W_{t}\left[i, z_{T}, l \mid \zeta_{t}\left(i, z_{T}, l\right)\right] & \equiv \pi \cdot S_{t}\left[i, z_{T}, l \mid \zeta_{t}\left(i, z_{T}, l\right)\right] \\
& =w_{t}\left[i, z_{T}, l \mid \zeta_{t}\left(i, z_{T}, l\right)\right]+\beta L_{t+1}\left[i, \zeta_{t}\left(i, z_{T}, l\right), l\right]-U_{t}(l),
\end{aligned}
$$

where $w$ denotes the current period wage. Simple algebra yields,

$$
\begin{aligned}
w_{t}\left[i, z_{T}, l \mid \zeta_{t}\left(i, z_{T}, l\right)\right]= & \pi \cdot\left\{y\left[i, \zeta_{t}\left(i, z_{T}, l\right), l\right]-h c \cdot p(t)\right. \\
& -s c\left[\zeta_{t}\left(i, z_{T}, l\right), z_{T}\right] \cdot p(t) \\
& +\beta O_{t+1}\left[i, \zeta_{t}\left(i, z_{T}, l\right), l\right]-\beta V_{t+1}\left(i, z_{s}^{\prime \prime}\right) \\
& -(1-\pi) \cdot\left\{\beta L_{t+1}\left[i, \zeta_{t}\left(i, z_{T}, l\right), l\right]-U_{t}(l)\right\} .
\end{aligned}
$$

Note that, because there is technological progess as well as a fixed cost of changing technologies, there will be an optimal rate at which the firm and worker jointly determine to upgrade, or switch, to the latest vintage. The lower the switching cost, the faster the rate of technology adoption. The faster the rate of technological progress, the greater the depreciation in the value of a match with an old technology (as the worker's threat point rises); as in Mortensen and Pissarides (1998b), the relationship between the upgrade (in their terminology, the implementation cost) and the increase in the unemployment benefit, will determine the effect of an increase in the rate of exogenous technological progress on joint match surplus.

\subsection{Value Functions}

\subsubsection{Value of Employment}

A worker who becomes or that remains unemployed this period earns an unemployment benefit, $b \cdot p(t)$, at the end of the period and will search for employment next period. The expected return from search next period depends on the thickness of the market, the distribution of vacancies across firm type, and the expected return from running into each type of firm. In equilibrium, the expected probability that an unemployed worker meets a vacant firm of type $\left(i, z_{T}\right)$ in period $t+1$ must be equal to the frequency of that type of meetings. Thus in equilibrium, surpressing vintage subscripts, 


$$
\begin{aligned}
U_{t}(l)= & b+\beta \cdot m\left(\theta_{t+1}\right) \sum_{i=1}^{I} \sum_{z=1}^{Z} f_{i z, t+1} \\
& \max \left\{\left[w_{t+1}\left[i, z, l \mid \zeta_{t+1}(i, z, l)\right]+\beta L_{t+2}\left[i, \zeta_{t+1}(i, z, l), l\right], U_{t+1}(l)\right\}\right. \\
& +\beta\left[1-m\left(\theta_{t+1}\right)\right] U_{t+1}(l) .
\end{aligned}
$$

An unemployed worker will meet no one on the labor market with probability $\left[1-m\left(\theta_{t+1}\right)\right]$, in which case the worker continues to be unemployed and searches the following period. A worker meeting noone is no better or worse off than a worker that has rejected a match.

\subsubsection{Continuation value of employment}

Those workers for whom matches have been terminated exogenously become unemployed. Workers in surviving matches have the choice of continuing the match or immediately receiving utility from unemployment. Suppressing vintage subscripts,

$$
L_{t}(i, z, l)=\delta U_{t}(l)+(1-\delta) \max \left\{w_{t}(i, z, l \mid z)+\beta L_{t+1}(i, z, l), U_{t}(l)\right\}
$$

Note that, given we have assumed that the list of technologies is fixed; although the technology type won't change, the vintage will be upgraded over time.

\subsubsection{Value of a vacancy}

Unlike unemployed workers, there is no benefit accrued to the vacant firm. Moreover, vacant firms pay a utility-denominated vacancy (or search) cost $v c$. $p(t)$ each period. The search cost is paid whether or not the firm meets a worker in the period. Conditional on meeting, a match is formed if the joint surplus is greater than or equal to zero. In case the firm does not meet a worker it remains vacant. Once again, in equilibrium, the probability that a firm meets a worker of a certain type must be equal to the frequency of that meeting. Vacant firms may choose to upgrade or change their technology type to improve the return from searching.

where we will assume throughout what follows that

$$
s c\left(z_{t}, z_{\tau}\right)=s c\left(z_{t}^{\prime}, z_{\tau}\right)=-s c\left(z_{\tau}, z_{t}\right)
$$


The return from searching is equal to

$$
\begin{aligned}
V_{t}\left(i, z_{T}\right)= & \max \left\{-v c \cdot p(t)+\frac{m\left(\theta_{t}\right)}{\theta_{t}} \sum_{l=1}^{L} f_{l, t} .\right. \\
& \max \left\{y\left[i, \zeta_{t}\left(i, z_{T}, l\right), l\right]-w_{t}\left[i, z_{T}, l \mid \zeta\left(i, z_{T}, l\right)\right]\right. \\
& -s c\left[\zeta\left(i, z_{T}, l\right), z_{T}\right] \cdot p(t)-h c \cdot p(t) \\
& \left.+\beta O_{t+1}\left[i, \zeta_{t}\left(i, z_{T}, l\right), l\right], \beta V_{t+1}\left(i, z_{s}^{\prime \prime}\right)\right\} \\
& \left.+\beta\left[1-\frac{m\left(\theta_{t}\right)}{\theta_{t}}\right] V_{t+1}\left(i, z_{s}^{\prime \prime}\right), 0\right\}
\end{aligned}
$$

\subsubsection{Continuation value of an operating firm}

As long as the menu of technologies is fixed, the continuing operating firm will never change technologies or break the match unless the match is terminated exogenously; the match pair will upgrade the current technology at the optimal rate, depending on the relation between $g$ and $s c\left(z_{t}, z_{T}\right)$. Those firms for which matches have been terminated exogenously become vacant and either enter the labor market the following period after making their technology adoption deci-

sion or they exit. Firms in surviving matches have the choice of continuing the match, searching the next period with the firm's optimal search technology, or exiting. Note that the firm only pays the operating cost $h c \cdot p(t)$ if the match is maintained. Suppressing the vintage subscripts,

$$
\begin{aligned}
O_{t}\left(i, z_{\tau}, l\right)= & \delta \beta\left[V_{t+1}\left(i, z_{s}^{\prime \prime}\right)-s c\left(z_{s}^{\prime \prime}, z_{\tau}\right) \cdot p(t)\right] \\
& +(1-\delta) \cdot \max \left\{y\left(i, \zeta_{t}\left(i, z_{\tau}, l\right), l\right)-w_{t}\left(i, z_{\tau}, l \mid \zeta_{t}\left(i, z_{\tau}, l\right)\right)\right. \\
& -s c\left[\zeta_{t}\left(i, z_{\tau}, l\right), z_{\tau}\right] \cdot p(t)-h c \cdot p(t) \\
& \left.+\beta O_{t+1}\left(i, \zeta_{t}\left(i, z_{\tau}, l\right), l\right), \beta V_{t+1}\left(i, z_{s}^{\prime \prime}\right)-s c\left(z_{s}^{\prime \prime}, z_{\tau}\right) \cdot p(t)\right\}
\end{aligned}
$$

\section{Equilibrium}

The firm entry condition and the steady-state derivation of the value functions, together with the flow equations into and out of unemployment, determine the long-run equilibrium of the system.

\subsection{Firm entry}

To close the model we assume that a new firm may enter the labor market (search for a worker) only after it has purchased a technology. Because the cost of entry increases at rate $g$ (as do all costs in the model) regardless of which vintage is purchased, new entrants will always search with the latest technology. The equilibrium value of a new entrant, $V_{t}\left(i, z_{t}\right)$, is equal to the cost of entry:

$$
V_{t}\left(i, z_{t}\right)=s c(z, 0) \cdot p(t)
$$


The equilibrium value of a vacant firm in period $t$ holding an older vintage will be tied down by the arbitrage conditions that the firm with the older vintage cannot gain by upgrading, nor can a firm with the latest vintage gain by downgrading, and then continuing to search.

$$
V_{t}\left(i, z_{t-n}\right)=s c(z, \emptyset) \cdot p(t)-s c\left(z_{t-n}, z_{t}\right) \cdot p(t)
$$

Firms for which that equilibrium does not hold will not exist in equilibrium $\left(f_{i z_{t-n}}=0\right)$ because they will have gained by either exiting or upgrading to the most recent vintage. The value of the upgrade or switching cost will determine the optimal rate at which vacant firms upgrade their capital stocks.

\subsection{Flows into and out of unemployment}

Steady-state equilibrium requires that the number of unemployed workers of each type remains constant over time. That requires that the flow out of unemployment equal the flow in. Defining $\chi(i, z, l)$ to be an indicator function of whether a match is formed or not, that flow condition is satisfied by.

$$
f_{l} \cdot u \cdot m(\theta) \cdot \sum_{i=1}^{I} \sum_{z=1}^{Z} \sum_{T=1}^{t}\left[f_{i z_{T}} \cdot \chi\left(i, z_{T}, l\right)\right]=\delta\left(\gamma_{l}-f_{l} \cdot u\right)
$$

\subsection{Equilibrium definition and computation}

An equilibrium is a list of time invariant:

- unemployment rate, $u$;

- market tightness, $\theta$;

- distribution of types across vacant firms, $f_{i z_{T}}$;

- distribution of types across unemployed workers, $f_{l}$;

- matching profiles, $\chi_{t}\left(i, z_{T}, l\right)$;

- and value functions $\left\{U_{t}(l), L_{t}\left(i, z_{T}, l\right), V_{t}\left(i, z_{T}\right), O_{t}\left(i, z_{T}, l\right)\right\}$

such that equations (1)-(9) hold.

In the following section we use numerical methods to characterize the equilibrium. Given parameter values we begin by guessing a matching profile $\left\{\chi_{t}\left(i, z_{T}, l\right)\right\}$. We then solve numerically the system of nonlinear equations (1)-(8) and verify that the conjectured matching profile is indeed an equilibrium. We repeat the procedure for all possible matching profiles to find the complete set of equilibria. ${ }^{10}$

\footnotetext{
${ }^{10} \mathrm{~A}$ copy of the program used together with the Fortran 90 programming code is available from the authors by request.
} 


\section{Examples}

We present numerical solutions to a parametrization of the model that satisfies three key assumptions needed to generate heterogenous technology adoption: workers are heterogenous; production synergies depend on the firm, worker, and technology type; and there are frictions in the matching process for workers and firms. The parameter values are chosen to make the model as simple as possible: we assume that there is no growth $(g=0)$, that there is only one type of firm, two types of worker (skilled and unskilled), and that technologies are rankable by all potential worker-firm pairs.

For the numerical examples that follow, we will assume the production matrix presented in Table $1 .{ }^{11}$

Table 1: Production Matrix y(z.l)

\begin{tabular}{|c|c|c|}
\hline tech \labor & Skilled & Unskilled \\
\hline High-Tech & 100 & 0 \\
\hline Low-Tech & 90 & 90 \\
\hline
\end{tabular}

In order to demonstrate the properties of the model, we show the effect on the number and characteristics of the equilibria under alternative specifications of parameters the value of which we believe to be closely linked to technological progress, namely a change in the cost of switching technologies, and change in the fraction of skilled workers in the labor force, and an addition to the menu of available technologies. The remaining parameter values were set equal to: $\beta=0.95, \delta=.05, \alpha=0.5, v c=h c=5, s c(z, \emptyset)=5$ for all $z, b=1$, $\pi=0.5$; these values were chosen somewhat arbitrarily and without regard to any attempt at calibration of the model to particular employment or wage distribution data. In the numerical solutions that follow, we show only the nontrivial equilibria in which both types of worker are employed; although other equilibria may exist we assume that in the long run workers would not choose training that would leave them unemployed with unit probability.

\subsection{Example without match-determined technology adop- tion}

We set the cost of changing technology prohibitively high in order to suppress the role of endogeneous changes in the use of technologies upon meeting with a worker. ${ }^{12}$ This reduces the model to the case studied in Albrecht and Vroman (1999). Under this parameterization, the firms' technology adoption decision is irreversible but nonetheless endogenous on the other parameter values in the

\footnotetext{
${ }^{11}$ Other parameter values were chosen fairly arbitrarily, without regard to calibrating the model to fit observed unemployment or vacancy rates, for example. In each of the cases we present in the text, the remaining parameter values were set equal to: $\beta=0.95, \delta=.05$, $\alpha=0.5, v c=h c=5, s c(z, \emptyset)=5$ for all $z, b=1, \pi=0.5$, and the ratio of firms to the labor force is equal to 4 .

${ }^{12}$ We set $s c\left(z^{\prime}, z\right)=s c\left(z, z^{\prime}\right)=200$ for this example.
} 
model; technology dispersion in this case is uninteresting since firm type is effectively, since permanently, linked to technology type. As in Albrecht and Vroman, there are multiple equilibria: a segmented equilibria in which skilled workers are picky and will only accept employment at a firm that has the hightech capital, and another equilbirum in which skilled workers accept employment at any firm, thus "crowding", in Albrecht and Vroman's terminology, the unskilled workers that can only work in the low-tech firm. There is wage disperision between skill groups in both equilibria; there is wage dispersion within the skilled-labor group in the crowding equilibrium.

Ranking of the equilibria in terms of welfare is ambiguous. Productivity (output per worker) and output are higher in the segmented equilibrium, but so too is the unemployment rate. Skilled worker wages are higher in the segmented equilibrium-this is necessary in equilibrium if skilled workers are not to regret having been more picky about their matches. Unskilled workers are worse off in the segmented equilibrium because there is less entry of firms holding the low-tech capital since they will not be able to use that capital to also match with skilled workers.

\section{Segmented Equilibrium: Wage dispersion between worker types}

Matching profile: highly skilled workers are patient, hold out for high-tech job

- Firms with high-tech match with skilled workers

- Firms with low-tech match with unskilled workers

\begin{tabular}{|c|c|c|c|c|c|c|c|}
\hline$u(\%)$ & $F$ & $v(\%)$ & $\theta$ & $f_{l=1}$ & $f_{z=1}$ & productivity & output \\
\hline 2.432 & 1.386 & 28.666 & 16.119 & .485 & .515 & 95.004 & 92.693 \\
\hline
\end{tabular}

Wages

\begin{tabular}{|c|c|c|}
\hline $\mathrm{z} \backslash \mathrm{l}$ & Skilled & Unskilled \\
\hline High-Tech & 90.5 & - \\
\hline Low-Tech & - & 80.8 \\
\hline
\end{tabular}

Crowding Equilibrium: Wage dispersion within and between worker types

Matching profile: highly skilled workers impatient

- Firms with high-tech match with skilled workers

- Firms with low-tech match with both worker types ("crowding equilibrium")

\begin{tabular}{|c|c|c|c|c|c|c|c|}
\hline$u(\%)$ & $F$ & $v(\%)$ & $\theta$ & $f_{l=1}$ & $f_{z=1}$ & productivity & output \\
\hline 1.594 & 1.239 & 20.555 & 15.97 & .388 & .372 & 91.865 & 90.401 \\
\hline \multicolumn{8}{|c|}{ Wages } \\
\hline & & $\mathrm{Z}$ & 1 & Skilled & \multicolumn{2}{|c|}{ Unskilled } & \\
\hline & & \multicolumn{2}{|c|}{ High-Tech } & 89.5 & - & & \\
\hline & & \multicolumn{2}{|c|}{ Low-Tech } & 84.5 & \multicolumn{2}{|c|}{81.6} & \\
\hline
\end{tabular}




\subsection{Example with match-determined technology adoption}

Sufficiently lowering the cost of technology capital eliminates the crowding equilibrium in the previous example; there are three possible equilibria in this example: the segmented equilibria from before, one in which skilled workers are willing to accept temporarily lower wages (indicated in parentheses in the tables) in exchange for upgrading to the high-tech capital, and one in which unskilled workers are willing to accept temporarily lower wages in exchange for downgrading to the low-tech capital. ${ }^{13}$

Lowering the cost of capital raises productivity and output relative to the crowding equilibrium. Relative to the segmented equilibrium, productivity and output are higher in both equilibria in which firms endogenously tailor their technology adoption decision to the worker characteristics. In all three equilibria, workers are paired with the technology that maximizes their potential output.

Lowering the cost of capital has ambiguous effects on unemployment: should the economy move to the segmented equilibrium, unemployment is either increased (relative to the crowding equilibria) or unchanged; should the economy move to either endogenous technology adoption equilibria, unemployment is reduced. The effects on wages are also ambiguous.

The "endogenous technology adoption" equilibria are consistent with the findings of Doms, Dunne, and Troske, that technology adoption decisions by U.S. manufacturers vary across firms within the same industry, and that the decision depends on the characteristics of the workforce in place or, in our terminology, on the production synergies of the current, rather than the expected, match.

Note also that there is wage dispersion within and between skill groups in both "endogenous technology adoption" equilibria that results from the cost of changing capital on joint worker-firm surplus. Also, skilled workers earn the highest wage in the equilibrium in which firms adopt technology to maximize the productivity of the low-skilled worker; this is because the costliness of matching with an unskilled worker lowers the firm's threat point and therefore increases the joint surplus (and therefore wages) from skilled-worker match.

Segmented Equilibrium: Firms cannot afford both to upgrade and to pay skilled-labor wages

Matching profile: skilled workers do not accept sharing switching cost

- Firms with high-tech match with skilled workers

- Firms with low-tech match with unskilled workers

\begin{tabular}{|c|c|c|c|c|c|c|c|}
\hline$u(\%)$ & $F$ & $v(\%)$ & $\theta$ & $f_{l=1}$ & $f_{z=1}$ & productivity & output \\
\hline 2.432 & 1.386 & 28.666 & 16.119 & .485 & .515 & 95.004 & 92.693 \\
\hline
\end{tabular}

Wages

\begin{tabular}{|c|c|c|}
\hline $\mathrm{z} \backslash \mathrm{l}$ & Skilled & Unskilled \\
\hline High-Tech & 90.5 & - \\
\hline Low-Tech & - & 80.8 \\
\hline
\end{tabular}

${ }^{13}$ We set $s c\left(z^{\prime}, z\right)=s c\left(z, z^{\prime}\right)=90$ for this example. 


\section{Endogenous Technolgy Adoption Equilibrium: Change technology to maximize skilled worker output}

Matching profile: Skilled workers accept sharing switching cost

- Firms with high-tech match with skilled workers

- Firms with low-tech match with skilled workers and then switch to hightech

- Firms with low-tech match with unskilled workers

\begin{tabular}{|c|c|c|c|c|c|c|c|}
\hline$u(\%)$ & $F$ & $v(\%)$ & $\theta$ & $f_{l=1}$ & $f_{z=1}$ & productivity & output \\
\hline 1.528 & 1.230 & 19.951 & 16.071 & .403 & .328 & 95.015 & 93.564 \\
\hline \multicolumn{8}{|c|}{ Wages } \\
\hline & & \multicolumn{2}{|c|}{$z \backslash 1$} & Skilled & \\
\hline & & \multicolumn{2}{|c|}{ High-Tech } & 90.4 & \multicolumn{2}{|c|}{ Unskilled } & \\
\hline & & \multicolumn{2}{|c|}{ Low-Tech } & $(45.4)$ & \multicolumn{2}{|c|}{809} & \\
\hline
\end{tabular}

Endogeous Technology Adoption Equilibrium: Change technology to maximize unskilled worker output

Matching profile: high-skilled don't accept switching cost, low-skilled do

- Firm with high-tech match with skilled workers

- Firms with high-tech match with unskilled workers and then switch to low-tech

- Firms with low-tech match with unskilled workers

\begin{tabular}{|c|c|c|c|c|c|c|c|}
\hline$u(\%)$ & $F$ & $v(\%)$ & $\theta$ & $f_{l=1}$ & $f_{z=1}$ & productivity & output \\
\hline 1.465 & 1.226 & 19.609 & 16.402 & .584 & .709 & 94.988 & 93.596 \\
\hline \multirow{2}{*}{\multicolumn{8}{|c|}{$\begin{array}{l}\text { Wages } \\
\text { Skilled }\end{array}$}} \\
\hline & & & & & & & \\
\hline & & \multicolumn{2}{|c|}{ High-Tech } & 91.6 & \multirow{2}{*}{\multicolumn{2}{|c|}{$\frac{(34.8)}{798}$}} & \\
\hline & & \multicolumn{2}{|c|}{ Low-Tech } & - & & & \\
\hline
\end{tabular}

\subsection{Example with relatively more skilled workers, capital expensive}

We solve the model for the case in which skilled workers make up 60 percent, rather than 50 percent, of the labor force, and in which the cost of changing technologies is prohibitively high. The crowding equilibrium is eliminated, and only the segmented equilibrium remains. The increase in the relative supply of skilled workers increases entry of firms holding the high-tech capital; consequently, skilled workers hold out for a match with that type of firm.

Average productivity increases relative to the earlier segmented (and therefore also the crowding) equilibrium because of the increase in mass of highly 
productive workers. The share of skilled workers in the unemployment distribution falls even though their number increases in the population; this is because of the strong entry of firms holding the high-tech capital relative to the previous segmented equilibrium.

Segmented Equilibrium: High probability of matching with a skilled worker

Matching profile: highly-skilled workers are impatient

- Firms with high-tech match with skilled workers

- Firms with low-tech match with unskilled workers

\begin{tabular}{|c|c|c|c|c|c|c|c|}
\hline$u(\%)$ & $F$ & $v(\%)$ & $\theta$ & $f_{l=1}$ & $f_{z=1}$ & productivity & output \\
\hline 2.402 & 1.365 & 28.516 & 16.213 & .534 & .568 & 96.016 & 93.710 \\
\hline \multicolumn{8}{|c|}{ Wages } \\
\hline & & \multicolumn{2}{|c|}{ High-Tech } & 90.9 & \multicolumn{2}{|c|}{ - } & \\
\hline & & \multicolumn{2}{|c|}{ Low-Tech } & - & \multicolumn{2}{|c|}{80.3} & \\
\hline
\end{tabular}

\subsection{Example with relatively more skilled workers, capital inexpensive}

We solve for the case in which the cost of changing technology is sufficiently cheap to allow for endogenous technology adoption and in which skilled workers make up 60 percent, rather than half, of the labor force. There is no crowding equilibrium because the net gain of endogenously changing technologies is positive. In this case there is also no segmented equilibrium because skilled workers, in relatively large supply, no longer have the bargaining power to refuse to share the technology switching cost.

Productivity and output increase relative to the case with fewer skilled workers since all matches maximize potential output as well as because there are more skilled-labor matches.

Endogenous Technology Adoption Equilibrium: change technology to maximize skilled worker output

Matching profile: skilled workers accept sharing switching cost

- Firms with high-tech match with skilled workers

- Firms with low-tech match with skilled workers and switch to high-tech

- Firms with low-tech match with unskilled workers

\begin{tabular}{|c|c|c|c|c|c|c|c|}
\hline$u(\%)$ & $F$ & $v(\%)$ & $\theta$ & $f_{l=1}$ & $f_{z=1}$ & productivity & output \\
\hline 1.638 & 1.247 & 21.115 & 16.082 & .451 & .457 & 96.025 & 94.453 \\
\hline \multicolumn{7}{|c|}{ Wages } \\
$\qquad$\begin{tabular}{|c|c|c|c|}
\hline $\mathrm{z} \backslash 1$ & Skilled & Unskilled \\
\hline High-Tech & 90.2 & - \\
\cline { 2 - 6 } Low-Tech & $(45.2)$ & 81.2 \\
\hline
\end{tabular}
\end{tabular}




\section{Endogenous Technology Adoption Equilibrium: change technology to maximize unskilled worker output}

Matching profile: low-skilled workers accept sharing switching cost

- Firms with high-tech match with skilled workers

- Firms with high-tech match with unskilled workers and switch to low-tech

- Firms with low-tech match with unskilled workers

\begin{tabular}{|c|c|c|c|c|c|c|c|}
\hline$u(\%)$ & $F$ & $v(\%)$ & $\theta$ & $\dot{f_{l=1}}$ & $f_{z=1}$ & productivity & output \\
\hline 1.317 & 1.205 & 18.119 & 16.577 & .632 & .873 & 95.996 & 94.731 \\
\hline \multicolumn{8}{|c|}{$\begin{array}{l}\text { Wages } \\
\text { Skilled }\end{array}$} \\
\hline & & \multicolumn{2}{|c|}{$\mathrm{z} \backslash 1$} & Skilled & \multicolumn{2}{|c|}{ Unskilled } & \\
\hline & & \multicolumn{2}{|c|}{ High-Tech } & 92.2 & \multirow{2}{*}{\multicolumn{2}{|c|}{$(34.1)$}} & \\
\hline & & \multicolumn{2}{|c|}{ Low-Tech } & - & & 79.1 & \\
\hline
\end{tabular}

\subsection{Example with technological innovation}

Technological innovation, as distinct from technological progress $(g>0)$, adds to the list of available technologies. The purpose of this exercise is to demonstrate how technological innovations may not only create new equilibria but also destroy old ones. It is that destruction of old matches that will lead to creative destruction between equilibria; the innovation (new high-tech) in Table 2 will not however lead to a decrease in long run aggregate productivity although such an innovation could occur.

Table 2: Production Matrix y(z.l)

\begin{tabular}{|c|c|c|}
\hline tech \labor & Skilled & Unskilled \\
\hline High-Tech & 100 & 0 \\
\hline Low-Tech & 90 & 90 \\
\hline New High-Tech & 105 & 85 \\
\hline
\end{tabular}

\subsection{1 three technologies, changing technologies expensive}

The high-productivity segmented equilibrium is eliminated from the set of equilibria that were possible before the introduction of the new high-tech capital. Only one matching profile satisfies equilibrium after the technological innovation-one in which skilled workers are patient and produce only with firms that have the new high-tech capital, but unskilled workers are impatient and accept employment with firms holding either the low-tech or the relatively unproductive new high-tech capital good. There is wage dispersion among unskilled workers.

The new equilibrium (shown below) results in lower wages for unskilled workers than in either of the equilibria when the production matrix was as in Table 1 since unskilled workers matched with the new high-tech capital produce less than 
with the low-tech capital, reducing unskilled worker threat point and therefore reducing the unskilled worker's wage in either match. Total output is higher after the introduction of the new high-tech capital because the increased output generated by skilled workers dominates the loss from unskilled workers. The welfare effect of the technologial innovation is ambiguous given the increased wage disperision between skill groups. Note too that nearly all firms carry the new technology, whereas holdings of the high-tech and low-tech capital had been much more balanced in the previous set of equilibria.

Crowding Equilibrium: wage dispersion between and within worker types

Matching profile: unskilled workers impatient

- Firms with low-tech match with unskilled workers

- Firms with new high-tech match with skilled and with unskilled workers

\begin{tabular}{|c|c|c|c|c|c|c|c|c|}
\hline$u(\%)$ & $F$ & $v(\%)$ & $\theta$ & $f_{l=1}$ & $f_{z=}$ & $f_{z=2}$ & productivity & output \\
\hline 1.218 & 1.948 & 17.326 & 16.984 & .508 & .000 & .033 & 95.080 & 93.921 \\
\hline \multicolumn{9}{|c|}{ Wages } \\
\hline & & \multirow{2}{*}{\multicolumn{2}{|c|}{$\begin{array}{c}\mathrm{z} \backslash \mathrm{l} \\
\text { High-Tech }\end{array}$}} & \multicolumn{2}{|c|}{ Skilled } & \multicolumn{2}{|c|}{ Unskilled } & \\
\hline & & & & \multicolumn{2}{|r|}{ - } & - & & \\
\hline & & \multicolumn{2}{|c|}{ Low-Tech } & & - & 80.5 & & \\
\hline & & \multicolumn{2}{|c|}{ New High-Tech } & \multicolumn{2}{|c|}{973} & 78.0 & & \\
\hline
\end{tabular}

\subsection{2 three technologies, capital inexpensive}

Relative to the "cheap capital" $\left(\operatorname{sc}\left(z^{\prime}, z\right)=90\right)$ case before the innovation of the third technology, all of the equilibria are destroyed; the only equlibrium is identical to the crowding equilibrium shown above; this is not an endogenous technology adoption equilibrium because the gain from changing from the new high-tech to the low-tech capital upon meeting an unskilled worker is too small relative to the cost. The only equilibrium in this case is identical to that in which capital was expensive. Unskilled workers as a group are worse off after the innovation because most of them are employed at firms holding the new high-tech, which offers a lower return than if they were producing the the lowtech capital, as they were (at least in the second period) before the innovation. Welfare effects of the technological innovation are ambiguous.

\subsection{Summary}

The model solutions generally contain multiple equilibria. The question of how an economic shock might affect the economy depends closely on expectations, which may determine both the starting and ending points. For example, if skilled workers did not believe that there was a good chance of meeting a firm holding the high-tech capital good (in the two-technology example), then a policy that lowered the cost of capital (capital gains tax reduction) or increased the 
fraction of skilled workers (education subsidy) would move the economy from a low-productivity crowding equilibrium to a higher-productivity segmented equilibrium. Consequently, the model is suggestive of a channel through which differences in economic policies might plausibly explain international differences in measured productivity, unemployment, and wage dispersion among countries with equal access to technological innovation and identical unemployment benefit programs. Indeed, the multiple equilibria generated in many specifications of the model suggest that significant differences in productivity, unemployment, and wage dispersion might result even if all fundamentals are identical. The examples in this section suggest that capital tax/subsidy and education policies can work to eliminate certain equilibria, should a policymaker wish to move the economy away from a particular steady-state (given some weighting in the state utility function). The next section discusses model dynamics between steady-states.

\section{Dynamics}

In general, only equations (1)-(8) need hold between long-run equilibria. Along the transition path, flows into and out of unemployment will not be in balance, nor, by implication, will the fraction of operating firms of each type be unchanging. From the previous section, we know that a change in fundamentals may have no affect on the equilibrium at all, in which case there are no model dynamics. Alternatively, a change in fundamentals or in expectations can cause the economy to move from one equilibrium to another. Because there is only one equilibrium per matching profile, $\{\chi(i, z, l)\}$, we can characterize the shift in the long-run equilibria as the dynamic response of a change in the matching profile (matches that firms and workers are willing to accept that also supports an equilibrium).

Denoting the initial and final equilibria by $A$ and $B$, respectively, we solve for the transition path by the following interative process:

- Acceptable matches change from the set $\left\{\chi_{A}(i, z, l)\right\}$ to the set $\left\{\chi_{B}(i, z, l)\right\}$

- Starting from the old unemployment distribution $\left\{f_{l}\right\}_{A}$, we know the number of employed workers in matches for which $\chi_{B}(i, z, l) \neq \chi_{A}(i, z, l)$ and therefore we know $\left\{f_{l}\right\}_{1}$ and total unemployment.

- Remaining unknowns: $\left\{f_{i z}\right\}, \theta=>i * z$ unknowns

- Equilibrium conditions: $V(i, z)=n c \cdot p(t)=>i * z$ equations

- We also know that the flow into employment for workers that have just left matches will be greater than the flow in because the number of operating firms using the new technology is less than in the steady state (in fact, it starts at zero). 
- Update $\left\{f_{l}\right\}_{1, \ldots T}$ and $\left\{f_{i z}\right\}$ as we iterate.

- Iteration complete (equilibrium) when equation (9) is satisfied.

There will be a U-shaped pattern to productivity in any situation in which there is a significantly large reallocation of workers and firms across matches. Thus the U-shaped pattern of productivity in the 1970s-1990s may have had nothing to do with technological innovation at all, but rather may have purely been the result of a series of shocks to the labor market, expectations, or capital costs. This result is a significant departure from other creative destruction models, which in general rely on learning economies or production externalities to get production first to fall and then to rise following a shock.

\section{Discussion: the "new economy"}

Recent theoretical work which has sought explanations for what appear to be at least two paradoxical developments in the U.S. economy over the past 20 or 30 years. First, significant technological innovations in high-tech (computer, communications equipment, and semiconductor) industries in the early 70s did not immediately lead to measured productivity gains. On the contrary, measured productivity growth followed a much more U-shaped pattern, falling off in the 70s and then accelerating in the 1990s after a period of moderate growth in the 1980s. Secondly, the notable rise in wage skill premium appears to have followed, rather than driven, the increase in the skill composition of the U.S. workforce, an increase which many date back to the incentives for young men to remain in school during the period of U.S. involvement in the Vietnam War. Analyses of these questions is further complicated by the rather different empirical properties of productivity and wage dispersion in other industrialized economies, which have had similar increases in skill composition and in

access to high-tech innovations and yet not had the same U-shaped pattern to productivity nor the increase in wage dispersion observed in the U.S. data.

We find that a model which focuses on the importance of complementarities between the technology characteristics and worker skills, or more specifically on the production synergies between the worker, firm, and technology characteristics, and in which there are frictions in the matching of those three inputs, can give us deeper insights into the empirical observations outlined above and which many have come to associate with the "new economy." There are three key assumptions in the model: (1) The technology adoption decision is endogenous on the availability of complementary inputs because there is more than one way to produce any good; (2) labor market frictions affect productivity and, thereby, also affect wages and wage dispersion; and (3) workers are heterogenous. 


\section{References}

Acemoglu, Daron (1998), "Why Do New Technologies Complement Skills? Directed Technical Change and Wage Inequality," Quarterly Journal of Economics November 1998, 1055-1089.

Acemoglu, Daron and Robert Shimer (1999), "Wage and Technology Dispersion," mimeo.

Aghion, Philippe and Peter Howitt (1994). "Growth and Unemployment," Review of Economic Studies 64, 477-494.

Albrecht, James and Susan Vroman (2000). "A Matching Model with Endogenous Skill Requirements," mimeo.

Blanchard, Olivier Jean and Peter Diamond (1989). "The Beveridge Curve," Brookings Papers on Economic Activity 1:1989, 1-60.

Chinhui, Juhn and Murphy, Kevin M., and Brooks Pierce (1993). "Wage Inequality and the Rise in Returns to Skill," Journal of Political Economy 101 No.3, 410-442.

Doms, Mark, and Dunne, Timothy, and Kenneth R. Troske (1997), "Workers, Wages, and Technology," Quarterly Journal of Economics 112, 253290.

Greenwood, Jeremy and Boyan Jovanovic (1998). "Accounting for Growth," forthcoming in Studies in Income and Wealth: New Directions in Productivity Analysis," Charles Hulten, ed., University of Chicago Press (for NBER).

Hobijn, Bart and Boyan Jovanovic (1999). "The Information Technology Revolution and the Stock Market: Preliminary Evidence," Mimeo.

Kiley, Michael T. (1999). "The Supply of Skilled Labour and Skill-Biased Technological Progress," forthcoming The Economic Journal 109 (October).

Mortensen, Dale T. and Christopher A. Pissarides (1998a). "New Developments in Models of Search in the Labor Market," Mimeo.

Mortensen, Dale T. and Christopher A. Pissarides (1998b). "Technologial Progress, Job Creation, and Job Destruction," Review of Economic Dynamics 1, 733-753.

Shi, Shouyong (1998). "Unskilled Workers in an Economy with SkillBiased Technology," CREFE Working Paper No. 73.

Siegel, Donald S. (1999). "Skill-Biased Technological Change: Evidence From a Firm-Level Study," W.E. Upjohn Institute for Employment Research.

Weil, David and Margaret Y. Hwang (1999). "The Diffusion of Modern Manufacturing Practices: Evidence from the Retail Apparel Sectors," Mimeo. 